\title{
Identificação de requisitos de qualidade demandados por usuários de biblioteca universitária: um estudo de caso
}

\author{
Identifying quality requirements demanded by university library users: a case study
}

Vítor Vasata Macchi Silva, Andreia Petró da Rosa, Ana Cláudia da Costa Leite, Rodrigo Silva Caxias de Sousa. Universidade Federal do Rio Grande do Sul.

\section{RESUMO}

Propõe melhorias relacionadas aos requisitos mais valorizados pelos usuários da Biblioteca Central de uma Universidade Federal identificados a partir de um estudo de usuários. Objetiva identificar o perfil dos usuários que frequentam essa Biblioteca e, também, os requisitos que esses mais valorizam em unidades de informação. Cinco etapas compõem o método de trabalho. São elas: caracterização do cenário; elaboração e aplicação do questionário; identificação do perfil dos usuários; identificação dos requisitos valorizados pelos usuários; e proposição de melhorias à Biblioteca. A metodologia utilizada para identificação dos requisitos é a proposta por Ribeiro et al. (2001). Os resultados indicam que a maioria dos usuários não utiliza o acervo disponível e, também, que as mesas de estudo correspondem ao principal motivo para ida dos usuários à Biblioteca. Os resultados indicam, ainda, que "Infraestrutura" é a categoria mais valorizada pelos usuários da Biblioteca em estudo. Além destes aspectos, os resultados apontam que os requisitos mais valorizados pelos usuários desta Biblioteca são "disponibilizar salas fechadas para trabalhos em grupo", "disponibilizar computadores para pesquisa" e "disponibilizar rede wi-fi". As propostas de melhoria se relacionam a esses requisitos. Aponta que o atendimento das propostas listadas pode contribuir para a melhoria da percepção dos usuários com relação aos serviços oferecidos pela Biblioteca.

PALAVRAS-ChavE: Estudo de usuário. Universidade Federal. Biblioteca central.

\section{ABSTRACT}

Proposes improvements related to the most valued requirements by the users of the Central Library of a Federal University, identified from a study of users. Aims to identify the profile of the users who attend this library and also the requirements that this users most value in information units. Five steps comprise the method of working. They are: characterization of the scene; development and implementation of the questionnaire; identification of the profile of the users; identification of requirements valued by users; and proposition of improvements to the Library. The results indicate that most users do not use the available collection and also that the study tables correspond to the main reason for users go to the library. The results also show that "Infrastructure" is the most prized category by library users in the study. The results also indicate that the most valued requirements by users of this library are "available closed rooms for group work", "available computers for research" and "provide wi-fi". The proposals for improvement relate to aspects linked to the library infrastructure. It points out that meeting the proposals listed can contribute to improving the perception of users to the services provided by the library.

KEYWORDS: User study. Federal University. Central library.

\section{Correspondência}

1 Vítor Vasata Macchi Silva.

Universidade Federal do Rio Grande do Sul

Porto Alegre, RS.

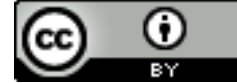

Email: vasata@hotmail.com

ORCID: http://orcid.org/0000-0001-8921-9727 


\section{INTRODUÇÃO}

A biblioteca, ao ser vista como uma organização que busca constantemente alcançar os resultados pretendidos (MACIEL; MENDONÇA, 2006), necessita da implantação de processos que objetivem a melhoria contínua em relação à prestação de serviços. A possibilidade de investigações relacionadas a essas organizações se constituem, desta forma, em estratégias que possibilitam à biblioteca competir, com maior acerto, no ambiente de inovações e incertezas que caracterizam a dinâmica de mercado das instituições sem fins lucrativos. Ademais, conforme pontuam Maciel e Mendonça (2006), observar o funcionamento das bibliotecas se constitui em uma forma de facilitar seu gerenciamento, de acrescentar qualidade aos seus produtos e serviços e, também, de evidenciar o seu papel junto às comunidades e seus usuários.

Nesse sentido os estudos de usuários se consolidam como alternativas que tem como objetivo saber o que os indivíduos necessitam em matéria de informação, ou saber se as necessidades de informação por parte dos usuários de uma biblioteca estão sendo satisfeitas de maneira adequada (FIGUEIREDO, 1994). Complementarmente, Figueiredo (1994) aponta que, a partir destes estudos, pode-se verificar por que, como e para quais fins os indivíduos usam informação e, também, quais fatores afetam seu uso. Sanz Casado (1994), por sua vez, define o estudo de usuários como um conjunto de estudos que procura tratar qualitativa e quantitativamente os hábitos de informação dos usuários mediante a aplicação de distintos métodos. Quanto às aplicações desses estudos, o autor destaca que essas podem se relacionar com aspectos como o conhecimento dos hábitos e necessidades de informação dos usuários e a adequação do espaço destinados a eles.

Estudos que considerem contribuições metodológicas de distintas áreas do conhecimento tem se consolidado como uma dinâmica recorrente na Ciência da Informação. Neste cenário, o Desdobramento da Função Qualidade, do inglês Quality Function Deployment (QFD), corresponde a um método que, segundo Ferreira (1997), pode ser utilizado para planejar, projetar e estruturar uma biblioteca moderna para os padrões de qualidade existentes, oriundo de uma interface que observa os processos de gestão a partir das áreas de engenharia e administração. A partir disto, aponta-se que a pesquisa aqui proposta se vale de etapas iniciais do QFD, a qual é utilizada de modo a identificar os aspectos mais valorizados pelos usuários e direcionar as tomadas de decisão gerenciais da Biblioteca em estudo.

Tais aspectos implicam em interpretar que o planejamento inicial da biblioteca pode requerer atualizações em função das condições em que a unidade de informação se encontra (FIGUEIREDO, 1994). Em contextos com tais características, os estudos de usuários têm como proposição rever aspectos centrais em relação aos tipos de serviços oferecidos, às estruturas organizacionais existentes, ao número de profissionais disponíveis e, também, aos recursos necessários para que a biblioteca cumpra a sua missão. Partindo destes aspectos, aponta-se que o estudo aqui proposto se fez necessário em função do desconhecimento do 
perfil e das necessidades de informação dos usuários da Biblioteca em análise, implicando em dificuldades relativas à realização de tarefas relacionadas à administração dessa unidade de informação. Dentre as dificuldades encontradas, está a ausência de um plano de identificação de requisitos que contemple a opinião dos usuários e que possa ser utilizado para orientar a alocação de recursos humanos e financeiros. Espera-se, desta forma, que a alocação dos recursos a partir da priorização dos requisitos contribua para a melhoria da percepção dos usuários a respeito dos produtos e serviços a eles oferecidos.

A partir dos elementos apresentados, pontua-se que o tema deste trabalho relaciona-se com o estudo de usuários da Biblioteca Central da Universidade Federal do Rio Grande do Sul. Tal estudo procura responder aos seguintes problemas de pesquisa: Qual o perfil dos usuários que frequentam essa Biblioteca? Quais os requisitos que esses usuários mais valorizam em unidades de informação? De modo complementar, destaca-se que o objetivo geral deste trabalho é propor melhorias relacionadas aos requisitos mais valorizados pelos usuários da Biblioteca a partir de um estudo de usuários. Os objetivos específicos são identificar o perfil dos usuários que frequentam essa Biblioteca e, também, os requisitos que esses mais valorizam em unidades de informação.

As próximas seções deste trabalho apresentam: $(i)$ o referencial teórico que embasa o estudo; (ii) o método de trabalho proposto para identificar o perfil e os requisitos mais valorizados pelos usuários da Biblioteca; (iii) o desenvolvimento do trabalho, que engloba as etapas de estruturadas para proposição de melhorias relacionadas aos requisitos mais valorizados pelos usuários; e (iv) as considerações finais sobre o trabalho desenvolvido.

\section{REVISÃO DE LITERATURA}

A administração de bibliotecas tem como finalidade assegurar que todas as funções desempenhadas no âmbito da unidade, independente do caráter (administrativo, técnico ou de serviços), sejam desenvolvidas com eficiência e eficácia, em consonância com a missão, os objetivos e as metas da instituição (MACIEL; MENDONÇA, 2006). A partir disso, segundo Maciel e Mendonça (2006), o planejamento, o controle e a avaliação constante do desempenho das bibliotecas configuram atividades de suma importância para sua vitalidade.

Maciel e Mendonça (2006) destacam ainda que o acúmulo de funções gerenciais, técnicas e informacionais por parte dos bibliotecários e, também, a falta de conhecimento desses profissionais sobre o histórico da biblioteca e sobre a comunidade a qual a biblioteca se dispõe a atender, constituem barreiras para administração das bibliotecas (MACIEL; MENDONÇA, 2006). Essas autoras apontam também que o planejamento e a elaboração de políticas de bibliotecas devem perpassar pelo estudo da comunidade de usuários. Tal estudo, segundo essas autoras, deve apresentar um diagnóstico do perfil dos usuários e indicar suas principais características, seus desejos e necessidades informacionais, seus hábitos de leitura e de frequência à biblioteca e tudo mais que for conveniente conhecer. 
Carvalho (2004) aponta que, dentro de um espaço universitário, é indispensável que haja o espaço de biblioteca, pois considera esse um dos espaços facilitadores da aprendizagem, visto que possibilita a troca de conhecimentos literários entre alunos, professores e funcionários. Além disto, segundo esse autor, a estrutura de uma biblioteca universitária só pode se tornar qualificada e eficaz se alimentada corretamente pela universidade que a rege. Afinal, essa estrutura não é autônoma, mas sim completamente dependente da universidade. De modo complementar, quanto à relação existente entre universidade e biblioteca, Ferreira (1980) destaca que pelo tipo e pela qualidade dos serviços prestados pela sua biblioteca, é possível medir-se o grau de desenvolvimento de uma universidade, pois já não se admite, em nossos dias, a possibilidade de um trabalho intelectual sério sem que o mesmo seja calcado em fontes bibliográficas atualizadas.

Quanto às bibliotecas centrais universitárias, Ferreira (1980) destaca que a biblioteca é o órgão que centraliza ou coordena de direito, ou de fato, as atividades biblioteconômicas e documentárias da universidade. A biblioteca central é vista, assim, como a administradora do sistema de todas as bibliotecas da universidade. Para uma universidade, possuir uma biblioteca central implica em ganhos, pois é esse núcleo que irá coordenar outras bibliotecas setoriais. Isso, segundo Ferreira (1980), faz com que determinados funcionários se destinem a tarefas de cunho administrativo das bibliotecas, e outros se destinem aos cuidados gerais de acervo e usuários e observem aspectos como aquisição, desbastamento de coleção e serviço de referência. Diante dessa diversidade de aspectos, e considerando a segmentação dos públicos e atividades nas bibliotecas centrais, os estudos de usuários se constituem em um instrumento de gestão fundamental à administração de bibliotecas.

Os estudos de usuários são necessários para conhecer e traçar o perfil dos usuários das unidades de informação, pois permitem reconhecer e identificar como as atividades podem ser desenvolvidas e administradas para que os níveis de satisfação apresentados pelos usuários sejam sempre elevados (NEVES; ANDRADE, 2012). Esses estudos são vistos, desta forma, como canais de comunicação que se abrem entre a biblioteca e a comunidade a qual ela serve (FIGUEIREDO, 1994). Desta forma, segundo Figueiredo (1994), os estudos de usuários podem ser entendidos como estudos necessários para ajudar a biblioteca na previsão da demanda ou da mudança da demanda de seus produtos ou serviços, o que permite que sejam alocados os recursos adequados, considerando a conjuntura na qual a biblioteca encontra-se inserida.

Quanto às funções dos estudos de usuários, Sanz Casado (1994) afirma que estes estudos subsidiam a avaliação dos recursos e da eficácia dos centros de informação, identificam adequações necessárias, relacionadas ao espaço físico e infraestrutura, e permitem reconhecer grupos homogêneos de usuários para posterior realização de treinamentos direcionados às necessidades específicas de cada grupo de indivíduos. Araújo (2008), por sua vez, ressalta que os estudos de usuários servem de instrumento para elaboração de um diagnóstico da situação atual. Sendo assim, apresentam um panorama da situação atual e permitem projeções para o futuro. 
A pesquisa de mercado executada na etapa inicial do Quality Fuction Deployment (QFD) corresponde a uma atividade que deve ser realizada para ouvir a voz dos clientes, para realizar o desdobramento da qualidade demandada por esses e, também, para identificar a importância dos itens da qualidade demandada por esses indivíduos (RIBEIRO et al., 2001). No âmbito das bibliotecas, tal pesquisa pode ser realizada, então, para identificar os aspectos que os usuários dessas unidades de informação mais valorizam nesses espaços. Como contribuição, destaca-se que a identificação de tais fatores pode direcionar a alocação dos recursos e contribuir para a melhoria da satisfação dos usuários com relação às bibliotecas.

\section{MATERIAIS E MÉTODOS}

Nesta seção são descritos: o (i) método de pesquisa e o (ii) método de trabalho utilizados neste estudo. A partir destas seções são descritas a metodologia de pesquisa utilizada e, também, as etapas estruturadas para que os objetivos propostos fossem atingidos.

\subsection{Caracterização do método de pesquisa}

Esta é considerada uma pesquisa aplicada, pois são investigados os meios pelos quais se pode desenvolver e aprimorar produtos, processos ou sistemas, com vistas à satisfação de uma necessidade específica e reconhecida (MIGUEL, 2012). Além disto, tal estudo também é considerado exploratório, pois busca identificar e/ou descrever características ignoradas até o momento da pesquisa; quantificar a frequência de algum fenômeno social; e/ou selecionar problemas ou áreas de interesse para a investigação (COUTINHO, 2014).

Quanto à abordagem, destaca-se que neste estudo é utilizada a abordagem mista. Isso se justifica, pois a abordagem qualitativa se caracteriza por observar o problema de pesquisa sob a perspectiva dos indivíduos (MIGUEL, 2012), enquanto a abordagem quantitativa é menos suscetível a vieses na coleta de dados. Neste cenário, segundo esse autor, uma forma de fortalecer as abordagens é combinando-as.

Além dos aspectos citados, destaca-se que esse trabalho corresponde a um estudo de caso, visto que busca o estudo profundo e exaustivo de um ou poucos objetos, de maneira a permitir seu amplo e detalhado conhecimento (GIL, 2010). Tais estudos são considerados adequados para a investigação de um fenômeno dentro de seu contexto real, onde os limites entre o fenômeno e o contexto não são claramente percebidos (YIN, 2005).

\subsection{Caracterização do método de trabalho}

A consecução dos objetivos propostos foi estruturada um método de trabalho organizado em etapas. Tais etapas são apresentadas na Figura 1. 


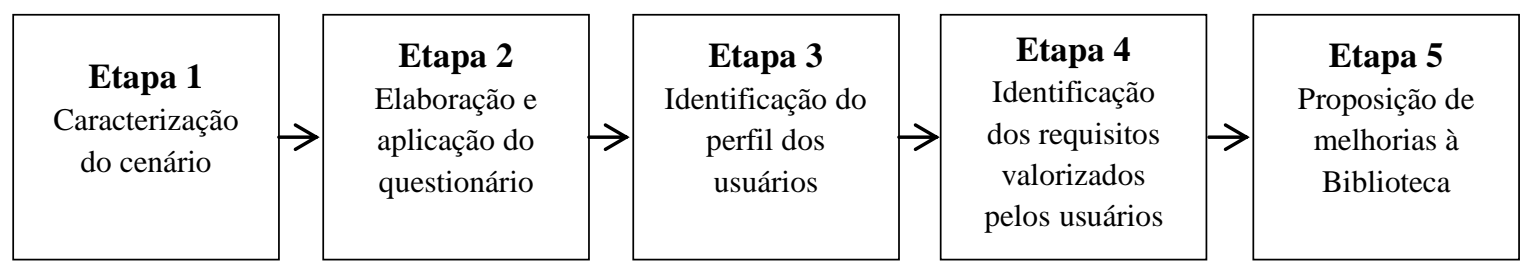

Figura 1. Etapas executadas para atingimento dos objetivos propostos Fonte: Elaborado pelos autores

Na etapa 1 foi caracterizado o cenário onde se encontra a Biblioteca. Para tanto, foram coletadas informações relacionadas aos ambientes externo e interno à Biblioteca. As informações vinculadas ao ambiente externo relacionaram-se a estrutura administrativa da Universidade e ao Sistema de Bibliotecas do qual a unidade em estudo faz parte. As informações relacionadas ao ambiente interno, por sua vez, se vincularam aos setores da Biblioteca e suas atribuições. Para coleta de tais informações, foram realizadas visitas à Biblioteca e, também, foram consultados os websites da Biblioteca e da Universidade em que essa se localiza.

Na etapa 2 foi elaborado e aplicado o questionário que buscou identificar o perfil e os requisitos mais valorizados pelos usuários da Biblioteca em estudo. Para elaboração de tal questionário, foram estabelecidas as características dos usuários que deveriam ser identificadas (idade, gênero, etc.). Além disto, foram estabelecidas as categorias dos requisitos a serem avaliados pelos usuários: infraestrutura, serviços, atendimento, acervo e acessibilidade. Neste âmbito, destaca-se que tais categorias foram selecionadas de forma a englobar os principais aspectos que podem interferir no atendimento aos usuários de uma biblioteca. Os requisitos que compuseram cada categoria, por sua vez, foram selecionados em função de sua potencial pertinência para os usuários da Biblioteca. $\mathrm{O}$ questionário elaborado e aplicado pode ser visualizado no Apêndice A.

Na terceira etapa foi identificado o perfil dos usuários da Biblioteca em análise. Para compilação e análise dos dados obtidos nos questionários foi utilizado o software excel. A apresentação dos resultados, por sua vez, privilegiou a apresentação percentual das distribuições observadas.

$\mathrm{Na}$ etapa 4 foram identificados os requisitos mais valorizados pelos usuários da unidades de informação em estudo. Para compilação e análise dos dados levantados nos questionários, também foi utilizado o software excel. A metodologia utilizada para identificação dos itens (requisitos) de qualidade demandada pelos usuários da Biblioteca em estudo foi a proposta por Ribeiro et al. (2001). Tal metodologia indica que a priorização dos requisitos deve ocorrer a partir da pontuação atribuída pelos usuários às categorias de requisitos (no caso: infraestrutura, serviços, atendimento, acervo e acessibilidade). $\mathrm{O}$ detalhamento da metodologia proposta por esses autores é realizado na seção 4.4. 
A quinta etapa objetivou a proposição das melhorias a serem implantadas de forma a atender aos requisitos mais valorizados pelos usuários. Para proposição de tais melhorias, foram utilizados os resultados obtidos e apresentados nas etapas 3 e 4 do método de trabalho.

\section{RESULTADOS}

Esta seção divide-se conforme as etapas estruturadas na caracterização do método de trabalho: (i) caracterização do cenário; (ii) elaboração e aplicação do questionário; (iii) identificação do perfil dos usuários; (iv) identificação dos requisitos valorizados pelos usuários; e (v) proposição de melhorias à Biblioteca.

\subsection{Caracterização do cenário}

A caracterização do cenário onde foi realizado o estudo foi dividida em duas seções distintas: (i) ambiente externo e (ii) ambiente interno. A primeira apresenta informações relativas à Universidade onde se encontra a Biblioteca; a segunda, por sua vez, informa aspectos relacionados aos setores da Biblioteca e suas atribuições.

\subsubsection{Ambiente externo}

No que diz respeito à Biblioteca Central (BC), destaca-se que esta Biblioteca corresponde a um órgão suplementar da Universidade, o qual corresponde ao órgão integrador e coordenador das Bibliotecas setoriais da Instituição. Destaca-se, ainda, quanto ao acervo que a Biblioteca gerencia, que $82,40 \%$ das quase 900 mil obras disponibilizadas pela Universidade correspondem a livros. Os usuários aptos a utilizar as Bibliotecas da Universidade, por sua vez, correspondem a aproximadamente 30 mil alunos, sendo que, deste montante, aproximadamente $67 \%$ correspondem a alunos de graduação.

\subsubsection{Ambiente interno}

A BC possui seis setores que administram atividades externas e internas. As atividades externas se caracterizam pela coordenação de todo o conjunto de Bibliotecas da Universidade. As atividades internas, por sua vez, são realizadas em setores divididos em:

- Direção: a qual administra o Sistema de Bibliotecas da Universidade e, também, a Biblioteca Central;

- $\quad$ Núcleo de Aquisição: setor que faz a gestão e operacionalização de processos de aquisição, desfazimento e descarte de materiais bibliográficos;

- Departamento de Serviços aos Usuários: setor que oferece produtos e serviços aos usuários, de modo a auxiliar na recuperação, no uso e na produção de informações;

- Departamento de Processos Técnicos: setor que realiza o tratamento da informação e seleção de doações; 
- Departamento de Obras Raras: setor que realiza o processamento técnico e a guarda do acervo de obras raras, bem como o atendimento aos pesquisadores destas obras;

- Laboratório de Conservação: setor que se responsabiliza pela preservação, conservação e restauração das obras da Biblioteca Central.

\subsection{Elaboração e aplicação do questionário}

Para elaboração do questionário a ser aplicado, a equipe de trabalho reuniu-se com o objetivo de identificar quais requisitos (aspectos de avaliação) deveriam ser analisados em cada uma das categorias. Nesta tarefa, a equipe preocupou-se em listar os principais aspectos que poderiam interferir na ida dos usuários à Biblioteca para atender suas necessidades de informação. Além disto, destaca-se que nem todos os requisitos listados no questionário correspondem a elementos que podem ser encontrados na Biblioteca. Com isto, buscou-se identificar se a unidade em análise pode incorporar alguns elementos que atualmente não são oferecidos, mas que são importantes para os usuários. Como exemplo, podem ser citados os requisitos "oferecer atendimento noturno" e "oferecer serviços de digitalização e reprografia (xerox)".

Além dos aspectos citados, destaca-se que a elaboração do questionário procurou obedecer a metodologia proposta por Ribeiro et al. (2001) que propõe, entre outros aspectos, que o número de requisitos em cada categoria deve ser aproximadamente o mesmo. Assim, as categorias foram organizadas de modo a apresentar sempre quatro ou cinco requisitos, quantidade considerada suficiente pela equipe de trabalho para observar os itens prioritários para os usuários. A aplicação do questionário, por sua vez, ocorreu durante o mês de Junho de 2015. A abordagem era aleatória e os usuários eram convidados a responder o questionário quando achassem melhor. Além disto, destaca-se que as abordagens ocorreram nos turnos da manhã e da tarde e, também, que 20 usuários aceitaram participar da pesquisa.

\subsection{Identificação do perfil dos usuários}

A identificação do perfil dos usuários ocorreu a partir da análise das respostas obtidas nos questionários aplicados. Neste âmbito, destaca-se que a idade média dos respondentes foi de 31,3 anos e que 55\% dos respondentes eram do sexo feminino. Quanto ao nível de escolaridade, destaca-se que $70 \%$ dos respondentes possuíam nível superior incompleto. Com relação ao vínculo dos usuários com a Universidade, destaca-se que $60 \%$ dos respondentes corresponderam a alunos de graduação. Quanto às áreas de interesse, destaca-se que os respondentes afirmaram possuir maior interesse nas áreas de Ciências Sociais Aplicadas (41,2\% do total de respondentes) e Ciências Humanas (35,3\%).

Quanto à frequência de uso da Biblioteca, destaca-se que o levantamento indicou que $60 \%$ dos respondentes afirma frequentar a Biblioteca mais de uma vez por semana, enquanto 
$20 \%$ afirmam frequentar a Biblioteca uma vez por semestre em média. Com relação à identificação dos motivos que levam os usuários à Biblioteca Central, destaca-se que esses deveriam ser avaliados da seguinte maneira: o motivo mais importante deveria possuir importância "1", o segundo mais importante deveria possuir importância " 2 " e assim sucessivamente. Posteriormente, a importância dos motivos que levam os usuários à Biblioteca foi analisada a partir da soma dos inversos dos pesos atribuídos pelos respondentes, como foi proposto por Ribeiro et al. (2001). Assim, por exemplo, se 5 respondentes classificaram um item como $2^{\circ}, 1^{\circ}, 4^{\circ}, 2^{\circ}, 2^{\circ}$, a soma dos inversos resulta na Equação 1. Desta forma, em um cenário com 5 respondentes, caso todos esses considerassem um aspecto como o mais importante, o somatório do inverso dos pesos seria igual a 5.

$$
\begin{aligned}
& \text { Equação 1. Exemplo de soma dos inversos } \\
& \qquad \frac{1}{2}+\frac{1}{1}+\frac{1}{4}+\frac{1}{2}+\frac{1}{2}=2,75 \\
& \text { Fonte: Adaptado de Ribeiro } \text { et al. (2001). }
\end{aligned}
$$

A partir dos dados levantados nos 20 questionários respondidos, foi identificado que o motivo que mais leva os usuários à Biblioteca é "utilização de mesas de estudo", o qual recebeu peso 9,75. Após esse motivo apareceram "uso de tecnologias" (peso 7,28), "consulta ao acervo" (4,98), "ambiente silencioso" $(4,83)$ e "busca de informação junto aos bibliotecários" $(2,83)$. Percebe-se, a partir destes aspectos, que os maiores pesos se referem à infraestrutura da Biblioteca - aspecto que demonstra uma tendência, por parte dos usuários, de utilização do espaço físico e dos recursos tecnológicos, em detrimento de aspectos como atendimento e consulta ao acervo.

Com relação ao comportamento de busca da informação dos respondentes, pode-se identificar que $88,2 \%$ dos usuários afirmam que buscam informações através de pesquisa no Sistema de Bibliotecas da Universidade, enquanto 11,8\% afirmaram que percorrem as estantes quando necessitam buscar alguma informação na Biblioteca. A partir destes resultados, pode-se perceber que tais resultados estão alinhados à análise que indica o baixo peso atribuído à atividade de busca de informação junto aos bibliotecários. Nesta questão destaca-se ainda que a opção de consulta ao bibliotecário não foi assinalada por nenhum dos respondentes. A partir dessas respostas, pode-se inferir que, majoritariamente, os usuários da Biblioteca em estudo apresentam um comportamento autônomo de busca à informação. Quanto à utilização do acervo pelos respondentes, pode-se identificar que 44,4\% dos respondentes afirmaram não utilizar o acervo da Biblioteca, enquanto 38,9\% dos respondentes afirmaram utilizar o acervo disponível para fins acadêmicos.

\subsection{Identificação dos requisitos valorizados pelos usuários}

A identificação dos requisitos valorizados pelos usuários ocorreu a partir do método proposto por Ribeiro et al. (2001). Tal método propõe que a equipe de pesquisa pode organizar as respostas a serem avaliadas no questionário quantitativo em estrutura de árvore, a 
qual deve refletir o desdobramento da qualidade demandada. O Quadro 1 apresenta a árvore da qualidade demandada estruturada pela equipe de trabalho.

Quadro 1. Árvore da qualidade demandada organizada pela equipe de trabalho

\begin{tabular}{|c|c|c|}
\hline Nível primário & Nível secundário & Nível terciário \\
\hline \multirow{4}{*}{ Planejamento } & \multirow{4}{*}{ Infraestrutura } & Disponibilizar computadores para pesquisa \\
\hline & & Disponibilizar mesas para estudo individual \\
\hline & & Disponibilizar rede $w i-f i$ \\
\hline & & Disponibilizar salas fechadas para trabalhos em grupo \\
\hline \multirow{5}{*}{ Processo } & \multirow{5}{*}{ Serviços } & Disponibilizar acervo impresso para empréstimo \\
\hline & & Capacitar usuários para uso de bases de dados \\
\hline & & Oferecer serviços de normalização de trabalhos acadêmicos \\
\hline & & Oferecer serviços de digitalização e reprografia (xerox) \\
\hline & & Oferecer agendamento para consulta a obras raras \\
\hline \multirow{5}{*}{ Processo } & \multirow{5}{*}{ Atendimento } & Oferecer atendimento à noite (18h às $22 \mathrm{~h})$ \\
\hline & & Oferecer atendimento aos sábados (8h às 12h) \\
\hline & & Fornecer auxílio nas pesquisas realizadas \\
\hline & & Oferecer atendimento online (chat) \\
\hline & & Oferecer atendimento multilíngue \\
\hline \multirow{4}{*}{ Planejamento } & \multirow{4}{*}{ Acervo } & Disponibilizar obras recentes de sua área de interesse \\
\hline & & Disponibilizar obras em bom estado de conservação \\
\hline & & Disponibilizar obras raras para consulta \\
\hline & & Possuir acervo digital \\
\hline \multirow{5}{*}{ Planejamento } & \multirow{5}{*}{ Acessibilidade } & Possuir sinalização fácil de ser entendida \\
\hline & & Ser fácil de ser acessada (portas amplas, rampas, poucos degraus) \\
\hline & & Possuir piso tátil (piso em alto relevo para caminhada segura) \\
\hline & & Ser acessível a Pessoas com Deficiência (PcD) \\
\hline & & Disponibilizar tecnologias assistivas (lupas, leitores de tela) \\
\hline
\end{tabular}

Fonte: Elaborado pelos autores

A partir da análise do Quadro 1, pode-se perceber que a equipe de trabalho classificou, no nível primário, os itens a serem avaliados em "planejamento" ou "processo". No nível secundário, por conseguinte, os requisitos foram classificados conforme as categorias estabelecidas pela equipe de trabalho: infraestrutura, serviços, atendimento, acervo e acessibilidade. O nível terciário, por sua vez, evidenciou os requisitos selecionados para serem avaliados pelos usuários.

Quanto ao desdobramento do método utilizado, Ribeiro et al. (2001) apontam que, no questionário fechado, podem ser atribuídos pesos aos itens de qualidade demandada. Para tanto, esses autores apontam que o questionário fechado pode questionar a importância que o cliente (no caso o usuário) atribui a cada item do nível secundário. Além disso, segundo esses autores, dentro de cada item do nível secundário, o questionário fechado pode avaliar a importância atribuída aos desdobramentos terciários identificados pela equipe de trabalho.

Segundo Ribeiro et al. (2001), a atribuição dos pesos aos itens da qualidade demandada do nível secundário pode ocorrer em termos comparativos, a partir da solicitação de que o respondente enumere os itens mais importantes (primeiro, segundo, terceiro, etc.). A partir disto, segundo esses autores, os pesos de cada item do nível secundário podem ser obtidos a partir da soma dos inversos. Apropriando-se disso, foi identificado o peso atribuído 
pelos respondentes às categorias. A Tabela 1 apresenta os pesos para o nível secundário identificados na Biblioteca em estudo.

Tabela 1. Pesos atribuídos às categorias de requisitos (nível secundário da árvore da qualidade)

\begin{tabular}{l|c}
\hline Nível secundário (Categoria) & $\begin{array}{c}\text { Peso identificado } \\
\text { na pesquisa }\end{array}$ \\
\hline Infraestrutura & 12,57 \\
\hline Serviços & 7,03 \\
\hline Atendimento & 6,70 \\
\hline Acervo & 9,57 \\
\hline Acessibilidade & 5,23 \\
\hline
\end{tabular}

Fonte: Elaborado pelos autores

A partir da análise da Tabela 1, pode-se identificar que os usuários atribuíram peso maior às categorias Infraestrutura e Acervo e peso menor à categoria Acessibilidade. Tais desempenhos devem-se, possivelmente, às características da Biblioteca e, também, ao fato de seu acervo físico ser composto essencialmente por obras de maior relevância histórica do que científica e, em sua maioria, ser restrito à consulta local.

Quanto aos pesos absolutos dos itens do nível terciário, esses autores afirmam que esses pesos podem ser identificados a partir da média aritmética das respostas de todos os respondentes (RIBEIRO et al., 2001). Ainda segundo Ribeiro et al. (2001), os graus de importância atribuídos pelos respondentes aos itens terciários da qualidade demandada devem ser transformados em pesos percentuais. Este procedimento, segundo esses autores, assegura que cada bloco terá o seu peso corretamente atribuído.

Para montagem da árvore da qualidade demandada que evidencia os pesos atribuídos pelos usuários, deve-se proceder, então, da seguinte forma:

- Primeiro: alocar os pesos das categorias do nível secundário na célula correspondente à categoria.

- Segundo: calcular o somatório dos pesos do nível secundário e alocar na célula correspondente. No caso, o valor alocado foi 41,10 .

- Terceiro: calcular o percentual de cada "peso da categoria" sobre o somatório de pesos e alocar na célula "peso \%" de cada categoria. Por exemplo, para a categoria "infraestrutura": $(12,57 / 41,10=30,58 \%)$.

- Quarto: alocar a média aritmética dos pesos dos requisitos atribuídos pelos respondentes nas células correspondentes aos requisitos.

- Quinto: calcular o somatório do peso dos requisitos de cada categoria e alocar na célula corresponde ao total da categoria. Por exemplo: para a categoria "acervo", $(6,78+6,83+4,94+6,11=24,66)$.

- Sexto: calcular o peso \% de cada requisito. Para tanto, nessa etapa deve-se multiplicar o peso do requisito pelo peso $\%$ da categoria e dividir esse resultado pelo peso total do requisito. Posteriormente, deve-se multiplicar o resultado obtido por 100 . 
A Equação 2 apresenta, como exemplo, o cálculo realizado para o requisito "Disponibilizar computadores para pesquisa".

Equação 2. Exemplo do cálculo do Peso \% de cada requisito

$$
6,65 * \frac{30,58 \%}{25,91} * 100=7,85
$$

Fonte: Elaborado pelos autores.

A Tabela 2 apresenta os pesos atribuídos pelos 20 respondentes às categorias e, também, aos requisitos analisados neste trabalho.

Tabela 2. Árvore da qualidade demandada e pesos atribuídos às categorias e aos requisitos

\begin{tabular}{|c|c|c|c|c|}
\hline $\begin{array}{c}\text { Nível } \\
\text { secun- } \\
\text { dário }\end{array}$ & $\begin{array}{l}\text { Peso } \\
\text { cate- } \\
\text { goria }\end{array}$ & Nível terciário & $\begin{array}{c}\text { Peso } \\
\text { requisito } \\
(\text { máximo 7) }\end{array}$ & Peso \% \\
\hline \multirow{4}{*}{$\begin{array}{l}\text { Infraes } \\
\text { trutura }\end{array}$} & \multirow{4}{*}{12,57} & Disponibilizar computadores para pesquisa & 6,65 & 7,85 \\
\hline & & Disponibilizar mesas para estudo individual & 6,00 & 7,08 \\
\hline & & Disponibilizar rede $w i-f i$ & 6,50 & 7,67 \\
\hline & & Disponibilizar salas fechadas para trabalhos em grupo & 6,76 & 7,98 \\
\hline & & $\begin{array}{lr}\text { Total categoria } \\
\end{array}$ & 25,91 & $30,58 \%$ \\
\hline \multirow{5}{*}{$\begin{array}{l}\text { Servi- } \\
\text { ços }\end{array}$} & \multirow{5}{*}{7,03} & Disponibilizar acervo impresso para empréstimo & 5,95 & 3,61 \\
\hline & & Capacitar usuários para uso de bases de dados & 6,06 & 3,67 \\
\hline & & Oferecer serviços de normalização de trabalhos acadêmicos & 5,33 & 3,23 \\
\hline & & Oferecer serviços de digitalização e reprografia (xerox) & 5,84 & 3,54 \\
\hline & & Oferecer agendamento para consulta a obras raras & 5,05 & 3,06 \\
\hline & & $\begin{array}{lr}\text { Total categoria } \\
\end{array}$ & 28,23 & $17,11 \%$ \\
\hline \multirow{5}{*}{$\begin{array}{l}\text { Atendi } \\
\text { mento }\end{array}$} & \multirow{5}{*}{6,70} & Oferecer atendimento à noite (18h às $22 \mathrm{~h})$ & 5,85 & 3,40 \\
\hline & & Oferecer atendimento aos sábados (8h às 12h) & 5,95 & 3,46 \\
\hline & & Fornecer auxílio nas pesquisas realizadas & 6,06 & 3,52 \\
\hline & & Oferecer atendimento online (chat) & 4,71 & 2,73 \\
\hline & & Oferecer atendimento multilíngue & 5,50 & 3,20 \\
\hline & & Total categoria & 28,06 & $16,30 \%$ \\
\hline \multirow{4}{*}{ Acervo } & \multirow{4}{*}{9,57} & Disponibilizar obras recentes de sua área de interesse & 6,78 & 6,40 \\
\hline & & Disponibilizar obras em bom estado de conservação & 6,83 & 6,45 \\
\hline & & Disponibilizar obras raras para consulta & 4,94 & 4,67 \\
\hline & & Possuir acervo digital & 6,11 & 5,76 \\
\hline & & Total categoria & 24,66 & $23,28 \%$ \\
\hline \multirow{5}{*}{$\begin{array}{l}\text { Aces- } \\
\text { sibilida } \\
\text { de }\end{array}$} & \multirow{5}{*}{5,23} & Possuir sinalização fácil de ser entendida & 6,79 & 2,83 \\
\hline & & Ser fácil de ser acessada (portas amplas, poucos degraus) & 5,95 & 2,48 \\
\hline & & Possuir piso tátil (piso em alto relevo para caminhada segura) & 5,37 & 2,24 \\
\hline & & Ser acessível a Pessoas com Deficiência (PcD) & 6,95 & 2,90 \\
\hline & & Disponibilizar tecnologias assistivas (lupas, leitores de tela) & 5,47 & 2,28 \\
\hline & & $\begin{array}{ll} & \text { Total categoria } \\
\end{array}$ & 30,52 & $12,73 \%$ \\
\hline $\begin{array}{l}\text { Soma- } \\
\text { tório }\end{array}$ & 41,10 & & & \\
\hline
\end{tabular}

Fonte: elaborado pelos autores.

A partir da análise da Tabela 2 pode-se perceber que o maior peso \% foi atribuído ao requisito "disponibilizar salas fechadas para trabalhos em grupo". Além disto, destaca-se que o requisito que obteve menor peso \% foi o requisito "possuir piso tátil (piso em alto relevo

\begin{tabular}{l|l|l|l|l|l} 
(C) RDBCI: Rev. Digit. Bibliotecon. Cienc. Inf. & Campinas, SP & v.15 & n.1 & p. 246-264 & jan./abr. 2017 \\
\hline
\end{tabular}


para caminhada segura)". A partir da análise dos resultados, pode-se observar que os requisitos mais valorizados pelos usuários se relacionam com a Infraestrutura da Biblioteca. Isso se justifica, pois os usuários privilegiaram, em suas respostas, a categoria "Infraestrutura".

\subsection{Proposição de melhorias à Biblioteca}

A partir da valorização fornecida pelos respondentes aos requisitos e categorias avaliadas neste estudo de usuários, foram observados aspectos que podem ser aprimorados na Biblioteca, os quais se relacionam com a Infraestrutura da Biblioteca. Os requisitos mais valorizados foram: "disponibilizar salas fechadas para trabalho em grupo", as quais não são disponibilizadas atualmente; "disponibilizar computadores para pesquisa", os quais são apenas cinco máquinas; e "disponibilizar rede wi-fi", a qual atualmente é disponível apenas para alunos e funcionários da Universidade. A partir destes elementos, foi sugerido à direção da Biblioteca considerar esses aspectos para que o espaço atenda de modo mais satisfatório aos aspectos considerados mais importantes pelos usuários da Biblioteca analisada.

\section{CONSIDERAÇõeS FINAIS}

O objetivo desse trabalho se constituiu na proposição de melhorias relacionadas aos requisitos mais valorizados pelos usuários da Biblioteca Central da Universidade Federal do Rio Grande do Sul, a partir de um estudo de usuários. Os objetivos específicos, por sua vez, eram identificar o perfil dos usuários que frequentam essa Biblioteca e, também, os requisitos que esses mais valorizam em unidades de informação. Tendo por base esses elementos, foi elaborado um método de trabalho dividido em cinco etapas. Os resultados obtidos em cada uma das etapas são apresentados a seguir.

Na primeira etapa foi realizada a caracterização do cenário onde foram identificadas informações relacionadas aos ambientes externo e interno à Biblioteca Central da Universidade. Tal etapa identificou, assim, elementos como contexto e atribuições. $\mathrm{Na}$ segunda etapa do método de trabalho foi elaborado e aplicado o questionário que visou identificar o perfil e os requisitos valorizados pelos usuários que frequentam a Biblioteca. $\mathrm{Na}$ terceira etapa foi realizada a identificação do perfil dos usuários. Neste âmbito, destaca-se que o perfil médio dos respondentes caracterizou-se pelos seguintes aspectos: possuir idade média de 31,3 anos, possuir nível superior incompleto e ser aluno de graduação da Universidade onde se situa a Biblioteca.

Na quarta etapa foi identificada a categoria e, também, os requisitos mais valorizados pelos respondentes. Neste âmbito, destaca-se que os usuários atribuíram importância maior à categoria "Infraestrutura", a qual teve peso $31 \%$ maior do que a segunda categoria mais valorizada (12,57 para Infraestrutura e 9,57 para Acervo). Quanto aos requisitos, destaca-se que aqueles que obtiveram peso percentual maior foram "disponibilizar salas fechadas para

\begin{tabular}{|c|c|c|c|c|c|}
\hline (C) RDBCI: Rev. Digit. Bibliotecon. Cienc. Inf. & Campinas, SP & v.15 & n.1 & p. 246-264 & jan./abr. 2017 \\
\hline
\end{tabular}


trabalhos em grupo", "disponibilizar computadores para pesquisa" e "disponibilizar rede wifi”. Tais resultados, assim como aqueles que evidenciaram o perfil dos respondentes, evidenciaram a autonomia dos usuários em seu comportamento de busca informacional. Isso se justifica, pois foram observados pesos maiores relacionados à infraestrutura da Biblioteca, a qual engloba mesas, computadores e redes. Pode-se inferir, assim, que tais resultados demonstram uma tendência, por parte dos usuários, de utilização do espaço físico e dos recursos tecnológicos, em detrimento de aspectos como atendimento e consulta ao acervo.

$\mathrm{Na}$ quinta etapa foram propostas melhorias a serem implantadas na Biblioteca em análise. Neste âmbito, pode-se destacar que as melhorias propostas se relacionaram com a disponibilização de salas para estudo em grupo, com a disponibilização de mais computadores para pesquisa e, também, de rede wi-fi que possa ser acessada pelo público geral. Por fim, espera-se que, a partir da incorporação dos aspectos citados na rotina da Biblioteca Central da Universidade Federal do Rio Grande do Sul, sejam melhorados os serviços oferecidos e, também, a percepção dos usuários em relação a essa unidade de informação. 


\section{IDENTIFICACIÓN DE LOS REQUISITOS DE CALIDAD DEMANDADOS POR USUARIOS DE BIBLIOTECA UNIVERSITARIA: UN ESTUDIO DE CASO}

\section{RESUMEN}

Propone mejoras relacionadas a los requisitos más valorados por los usuarios de la Biblioteca Central de una Universidad Federal identificados a partir de un estudio de usuarios. Objetiva identificar el perfil de los usuarios que frecuentan esa Biblioteca y, también, los requisitos que esos más valoran en unidades de información. Cinco etapas componen el método de trabajo. Son ellas: caracterización del escenario; elaboración y aplicación del cuestionario; identificación del perfil de los usuarios; identificación de los requisitos valorados por los usuarios; y proposición de mejoras a la Biblioteca. La metodología utilizada para identificación de los requisitos es la propuesta por Ribero et al. (2001). Los resultados indican que la mayoría de los usuarios no utiliza el acervo disponible y, también, que las mesas de estudio corresponden al principal motivo para la ida de los usuarios a la Biblioteca. Los resultados aún indican que la "Infraestructura" es la categoría más valorada por los usuarios de la Biblioteca en estudio. Además de estos aspectos, los resultados apuntan a que los requisitos más valorados por los usuarios de esta Biblioteca son "ofrecer salas cerradas para trabajos en grupo", "ofrecer computadoras para investigación" y "ofrecer red wi-fi". Las propuestas de mejora se relacionan a esos requisitos. Apunta que la atención a las propuestas presentadas puede contribuir para la mejora de la percepción de los usuarios con relación a los servicios ofrecidos por la Biblioteca.

Palabras clave: Estudio de usuario. Universidad Federal. Biblioteca Central.

Submetido em: 19/12/2016

Aceito em: 19/12/2016

Publicado em: 19/12/2016

\section{REFERÊNCIAS}

ARAÚJO, Carlos Alberto Ávila. Estudos de usuários: pluralidade teórica, diversidade de objetos. In: IX ENCONTRO NACIONAL DE PESQUISA EM CIÊNCIA DA

INFORMAÇÃO, Anais..., São Paulo. 2008. p. 1-14. Disponível em: <http://bogliolo.eci.ufmg.br/downloads/ARAUJO\%20Enancib\%202008.pdf >. Acesso em: 18 abr. 2016.

CARVALHO, Isabel Cristina Louzada. A socialização do conhecimento no espaço das bibliotecas universitárias. Rio de Janeiro: Interciência, 2004.

COUTINHO, Clara Maria Pereira. Metodologia de investigação em ciências sociais e humanas: teoria e prática. 2. ed. Coimbra: Almedida, 2014.

FERREIRA, Ângela de Moura. Desdobramento da qualidade em serviços: o caso da biblioteca da Escola de Engenharia da UFRGS. 1997. 176 f. Dissertação (Mestrado 
Acadêmico em Engenharia de Produção). Universidade Federal do Rio Grande do Sul (UFRGS), Porto Alegre, 2012.

FERREIRA, Lusimar Silva. Bibliotecas universitárias brasileiras. São Paulo: Pioneira, 1980.

FIGUEIREDO, Nice Menezes de. Estudos de uso e usuários da informação. Brasília: IBICT, 1994.

GIL, Antônio Carlos. Como elaborar projetos de pesquisa. 5. ed. São Paulo: Atlas, 2010.

MACIEL, Alba Costa; MENDONÇA, Marília Alvarenga Rocha. Funções na fase de dinamização das coleções. In: MACIEL, Alba Costa; MENDONÇA, Marília Alvarenga Rocha. Bibliotecas como organizações. Rio de Janeiro: Interciência, 2006.

MIGUEL, Paulo Augusto Cauchick (Coord.) et al. Metodologia de pesquisa em engenharia de produção e gestão de operações. 2. ed. Rio de Janeiro: Elsevier, 2012.

NEVES, Dulce Amélia de Brito; ANDRADE, Wendia Oliveira de. Usuários da informação jurídica: quem são e como funciona o fluxo informacional no âmbito do arquivo da Justiça Federal da Paraíba. Biblionline, João Pessoa, v. 8, n. esp., p. 55-64, 2012. Disponível em: <http://periodicos.ufpb.br/ojs2/index.php/biblio/article/view/14190>. Acesso: 18 mar 2016.

RIBEIRO, José Luis Duarte; ECHEVESTE, Márcia Elisa; DANILEVICZ, Ângela de Moura Ferreira. A utilização do QFD na otimização de produtos, processos e serviços. Porto Alegre: FEENG/UFRGS, 2001.

SANZ CASADO, Elías. Estudios de usuarios: conceptos básicos. In: SANZ CASADO, Elías. Manual de estudios de usuários. Madrid: Pirámide, 1994. Cap. 2. p. 19-44.

YIN, Robert K. Estudo de caso: planejamento e métodos. 3. ed. Porto Alegre: Bookman, 2005.

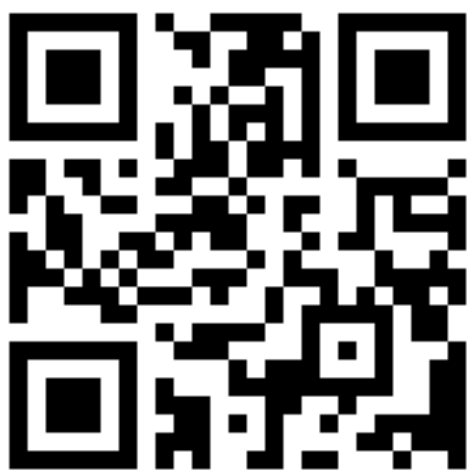




\section{APÊNDICE A}

Esta pesquisa procura identificar o perfil dos usuários da Biblioteca Central desta Universidade. Procura, também, identificar os requisitos que são valorizados pelos usuários dessa Biblioteca. As perguntas são todas objetivas. Desde já, agradecemos sua participação.

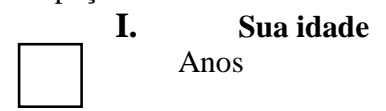

II. Gênero
Feminino

Masculino

\section{Seu nível de escolaridade}

$\square$ Nível fundamental incompleto

$\square$ Nível fundamental

$\square$ Nível médio incompleto

$\square$ Nível médio

$\square$ Nível superior incompleto

$\square$ Nível superior

$\square$ Pós-graduação (Especialização)

$\square$ Pós-graduação (Mestrado)

$\square$ Pós-graduação (Doutorado)

\section{Seu vínculo com a Universidade}

$\square$ Não possuo vínculo com a Universidade

$\square$ Aluno de graduação

$\square$ Aluno de pós-graduação

$\square$ Docente

$\square$ Aluno de educação básica

$\square$ Aluno de educação profissional

Técnico administrativo

\section{V. Área do conhecimento do seu interesse (marque somente uma alternativa)}

$\square$ Ciências Exatas e da Terra (Matemática, Estatística, Ciência da Computação, Física, Química, Geociências, Ciências Biológicas)

$\square$ Engenharias (Civil, Minas, Materiais, Metalúrgica, Química, Mecânica, Produção, Elétrica, Outras Engenharias)

$\square$ Ciências da Saúde (Medicina, Nutrição, Odontologia, Farmácia, Enfermagem, Educação Física, Fonoaudiologia, Fisioterapia)

$\square$ Ciências Agrárias (Agronomia, Zootecnia, Medicina Veterinária)

$\square$ Ciências Sociais Aplicadas (Direito, Administração, Economia, Arquitetura, Ciência da Informação, Comunicação, Serviço Social)

$\square$ Ciências Humanas (Filosofia, Sociologia, História, Geografia, Psicologia, Educação, Relações Internacionais)

$\square$ Linguística, Letras e Artes

\section{Sua frequência média de uso da Biblioteca Central}

$\square$ Mais de uma vez por semana

$\square$ Uma vez por semana

$\square$ Uma vez por mês

$\square$ Uma vez por semestre

$\square$ Uma vez por ano

VII. Enumere de 1 a 5 os motivos que te levam à Biblioteca Central

Aqui você deve ordenar de 1 a 5 os motivos (sendo 1 - mais importante, 2 - segundo mais importante, [ ... ] e 5 - menos importante).

$\square$ Consulta ao acervo

$\square$ Uso de tecnologias (internet, wi-fi, scanner)

$\square$ Utilização das mesas de estudo

$\square$ Busca de informação junto aos Bibliotecários

Ambiente silencioso

VIII. Sua principal forma de buscar a informação ou documento de interesse (marque somente uma alternativa)

$\square$ Solicita ao Bibliotecário

$\square$ Pesquisa no sistema de automação de Bibliotecas da Universidade

$\square$ Percorre as estantes

$\square$ Outra. Qual?

\section{Quanto à utilização do acervo, você:}


$\square$ Utiliza para fins acadêmicos (estudo, trabalhos de disciplinas)

$\square$ Utiliza para uso profissional

$\square$ Utiliza para lazer, curiosidades pessoais

$\square$ Não utiliza o acervo

Instruções gerais: Responder as questões marcando com um "x" na importância do requisito para você. Ao final, ordenar a importância dos quesitos.

\section{Quanto à INFRAESTRUTURA da Biblioteca}

Disponibilizar computadores para pesquisa

Pouco importante $\square 1 \square 2 \square 3 \square 4 \square 5 \square 6 \square 7$ Muito importante

Disponibilizar mesas para estudo individual

Pouco importante $\square 1 \square 2 \square 3 \square 4 \square 5 \square 6 \square 7$ Muito importante Disponibilizar rede wi-fi

Pouco importante $\square 1 \square 2 \square 3 \square 4 \square 5 \square 6 \square 7$ Muito importante Disponibilizar salas fechadas para trabalhos em grupo

Pouco importante $\square 1 \square 2 \square 3 \square 4 \square 5 \square 6 \square 7$ Muito importante

XI. Quanto aos SERVIÇOS da Biblioteca

Disponibilizar acervo impresso para empréstimo

Pouco importante $\square 1 \square 2 \square 3 \square 4 \square 5 \square 6 \square 7$ Muito importante Capacitar usuários para uso de bases de dados

Pouco importante $\square 1 \square 2 \square 3 \square 4 \square 5 \square 6 \square 7$ Muito importante Oferecer serviços de normalização de trabalhos acadêmicos

Pouco importante $\square 1 \square 2 \square 3 \square 4 \square 5 \square 6 \square 7$ Muito importante Oferecer serviços de digitalização e reprografia (xerox)

Pouco importante $\square 1 \square 2 \square 3 \square 4 \square 5 \square 6 \square 7$ Muito importante Oferecer agendamento para consulta a obras raras

Pouco importante $\square 1 \square 2 \square 3 \square 4 \square 5 \square 6 \square 7$ Muito importante

XII. Quanto ao ATENDIMENTO da Biblioteca

Oferecer atendimento à noite (18h às $22 \mathrm{~h})$

Pouco importante $\square 1 \square 2 \square 3 \square 4 \square 5 \square 6 \square 7$ Muito importante Oferecer atendimento aos sábados (8h às $12 \mathrm{~h}$ )

Pouco importante $\square 1 \square 2 \square 3 \square 4 \square 5 \square 6 \square 7$ Muito importante Fornecer auxílio nas pesquisas realizadas

Pouco importante $\square 1 \square 2 \square 3 \square 4 \square 5 \square 6 \square 7$ Muito importante Oferecer atendimento online (chat)

Pouco importante $\square 1 \square 2 \square 3 \square 4 \square 5 \square 6 \square 7$ Muito importante Oferecer atendimento multilíngue

Pouco importante $\square 1 \square 2 \square 3 \square 4 \square 5 \square 6 \square 7$ Muito importante

\section{Quanto ao ACERVO da Biblioteca}

Disponibilizar obras recentes de sua área de interesse

Pouco importante $\square 1 \square 2 \square 3 \square 4 \square 5 \square 6 \square 7$ Muito importante Disponibilizar obras em bom estado de conservação

Pouco importante $\square 1 \square 2 \square 3 \square 4 \square 5 \square 6 \square 7$ Muito importante Disponibilizar obras raras para consulta

Pouco importante $\square 1 \square 2 \square 3 \square 4 \square 5 \square 6 \square 7$ Muito importante Possuir acervo digital

Pouco importante $\square 1 \square 2 \square 3 \square 4 \square 5 \square 6 \square 7$ Muito importante

\section{Quanto à ACESSIBILIDADADE da Biblioteca}

Possuir sinalização fácil de ser entendida

Pouco importante $\square 1 \square 2 \square 3 \square 4 \square 5 \square 6 \square 7$ Muito importante Ser fácil de ser acessada (portas amplas, rampas, poucos degraus) Pouco importante $\square 1 \square 2 \square 3 \square 4 \square 5 \square 6 \square 7$ Muito importante Possuir piso tátil (piso em alto relevo para caminhada segura)

Pouco importante $\square 1 \square 2 \square 3 \square 4 \square 5 \square 6 \square 7$ Muito importante Ser acessível a Pessoas com Deficiência (PcD)

Pouco importante $\square 1 \square 2 \square 3 \square 4 \square 5 \square 6 \square 7$ Muito importante 


\section{Disponibilizar tecnologias assistivas (lupas, leitores de tela, suportes para leitura)}

Pouco importante $\square 1 \square 2 \square 3 \square 4 \square 5 \square 6 \square 7$ Muito importante

\section{Enumere de 1 a 5 os quesitos que você valoriza em uma biblioteca}

Aqui você deve ordenar de 1 a 5 os aspectos mais importantes (sendo 1 - mais importante, 2 - segundo mais importante, [ . . . ] e 5 - menos importante).

$\square$ Infraestrutura (computadores, mesas, rede, salas)

$\square$ Serviços (empréstimo, capacitação, normalização, digitalização, agendamento)

$\square$ Atendimento (atendimento noturno, aos sábados, online, multilíngue, auxílio)

$\square$ Acervo (atualização, estado de conservação, obras raras, acervo digital)

$\square$ Acessibilidade (sinalização, acesso, piso, acessibilidade a PcD, tecnologias assistivas) 